\title{
Combination of minocycline and rifampicin against methicillin- and gentamicin-resistant Staphylococcus
}

\section{aureus}

\author{
E YOURASSOWSKY, MP VAN DER LINDEN, MJ LISMONT, F CROKAERT
}

From the Hôpital Universitaire Brugmann, Service de Biologie Clinique, 1020 Bruxelles, Belgique

SUMMARY Methicillin- and gentamicin-resistant Staphylococcus aureus may remain sensitive to minocycline and to rifampicin. A study of growth curves has shown that at inhibitory concentrations $(0.4 \mu \mathrm{g} / \mathrm{ml})$, minocycline prevents the development of mutants resistant to rifampicin.

Staphylococcus aureus resistant to methicillin and gentamicin is responsible for an increasing number of hospital infections, some of which are severe. ${ }^{1-7} \mathrm{~A}$ number of treatments have been suggested although vancomycin is often the only major antibiotic which is active against these strains. However, it is necessary to assess the effect of the "second choice" antibiotics. The risk of rapid development of resistance to rifampicin is well known, ${ }^{89}$ and in spite of the excellent penetration particularly in polymorphonuclear cells of this antibiotic, ${ }^{10} 11$ its use alone is contraindicated. Minocycline is active against Staph aureus, ${ }^{12-14}$ including multi-resistant strains, particularly those resistant to tetracycline and methicillin. ${ }^{15-17}$ The minocycline minimal inhibitory concentrations (MICs) are compatible with a therapeutic effect.

A combination of minocycline and rifampicin was investigated in vitro (a) to demonstrate whether a synergistic or antagonistic effect was present, and (b) to determine the protective effect of minocycline against rifampicin resistance.

\section{Material and methods}

MICROBIALST RAINS

Between January and September 1979, most strains of Staph aureus isolated at the Brugmann University Hospital showed a high resistance pattern: they were resistant not only to $\beta$-lactam antibiotics (penicillin, methicillin, cloxacillin, cephalosporins) but also to gentamicin (the gentamicin MICs were $>12.5 \mu \mathrm{g} / \mathrm{ml}$ ) but all these strains were susceptible to minocycline according to the Kirby Bauer method. ${ }^{18}$ Three

Accepted for publication 21 October 1980 strains of different phage type were selected for this investigation.

\section{Microbial strains}

Minocycline HCL (Cyanamid Benelux, batch no 7116B-172). Rifampicin (Lepetit, batch no $\mathrm{P} / 4$ ) (solution in dimethyl formamide). The MICs of minocycline (tube dilution method in Mueller Hinton medium, inoculum $10^{6}$ micro-organisms $/ \mathrm{ml}$ ) were $0.2 \mu \mathrm{g} / \mathrm{ml}$ for all the strains. Rifampicin showed minimal inhibitory activity in liquid medium up to a concentration of $0.01 \mu \mathrm{g} / \mathrm{ml}$. However, this value was uncertain because of the possible occurrence of the "skip phenomenon." This one-step resistance was not predictable and might occur at any concentration between $0.01 \mu \mathrm{g} / \mathrm{ml}$ and $6.4 \mu \mathrm{g} / \mathrm{ml}$ of rifampicin.

\section{GROWTH CURVES}

Densitometric measurement of bacterial growth was carried out using an Abbott MS-2 apparatus ${ }^{19}$ and a simple multichambered cuvette (5996-01 research cartridges).

\section{CULTURE MEDIA}

Iso-sensitest (Oxoid, Basingstoke, Hampshire, England).

STANDARDISATION OF CULTURES

Before the cultures were introduced into the multichambered cuvette, each strain was pre-incubated in culture with agitation for six hours. The microbial density was determined with a spectronephelometer (Spekol, Jena) and adjusted by dilution to 0.5 on the McFarland scale of bacterial density. The culture was then diluted $1 / 100$ to obtain $2 \times 10^{6}$ viable units $/ \mathrm{ml}$. 
Samples of the bacterial suspension $(1.4 \mathrm{ml})$ were introduced into each chamber of the multichambered cuvette, and these were then transferred to the measuring unit of the MS-2 apparatus.

The antibiotic combination $(0.1 \mathrm{ml}$ in iso-sensitest medium) was added to the chambers at time zero during the exponential phase of growth so as to obtain concentrations of $6.4 \mu \mathrm{g} / \mathrm{ml} ; 3.2 \mu \mathrm{g} / \mathrm{ml}$; $1.6 \mu \mathrm{g} / \mathrm{ml}$; and so on. Each concentration of minocycline in the combination was studied against all the concentrations of rifampicin. The growth curve was recorded from the time that the antibiotic was added to the chamber (time zero on the abscissa of figure).

The growth curves were produced on a video screen (Tektronix 4006-1) from densitometric values obtained at five-minute intervals for 20 hours on magnetic tape. The biomass was expressed in logarithms $\mathrm{N}_{2}$ of the increase in optical density.

DETECTION OF ONE STEP RESISTANCE TO

RIFAMPICIN AS WELL AS BACTERICIDAL

ACTIVITY

After 20 hours' incubation, $0 \cdot 1 \mathrm{ml}$ from each chamber was inoculated over the entire surface of a $9 \mathrm{~cm}$ diameter Petri dish containing $10 \mathrm{ml}$ of Iso-sensitest and $1.5 \%$ agar. A disc containing $10 \mu \mathrm{g}$ rifampicin was placed in the centre of the Petri dish. The number of colonies developing after 24 hours on the Petri dish was assessed semi-quantitatively. Absence of growth (or $<10$ colonies) was given the score $\pm ; 10$ to 100 colonies $+; 100$ to 1000 colonies ++ ; and $>1000$ colonies (or a confluent culture) +++ . Strains whose colonies were seen up to the rifampicin disc were regarded as resistant. The MIC of these was $>100 \mu \mathrm{g} / \mathrm{ml}$. No case of "one step" resistance to minocycline was seen.

\section{Results}

In spite of the fact that the three strains of Staph aureus were of different lysotypes, the results were very similar. The figure shows the profile of the growth curves obtained. Minocycline produced total inhibition of the growth of the microbial strains at a concentration of $0.4 \mu \mathrm{g} / \mathrm{ml}$. At lower concentrations growth was slow and became even slower as the concentration of minocycline approached the MIC. No antibacterial effect has been detected at $0.01 \mu \mathrm{g} / \mathrm{ml}$ minocycline concentration and the curve was similar to the control. In the case of rifampicin, a regrowth of cultures was observed at concentrations between 0.04 and $6.4 \mu \mathrm{g}$ rifampicin $/ \mathrm{ml}$ and was seen after $14 \pm 2$ hours incubation. This time was independent of the rifampicin concentrations. The regrowth did not always occur ("skip phenomenon" due to "one step" resistance). The rate of bacterial
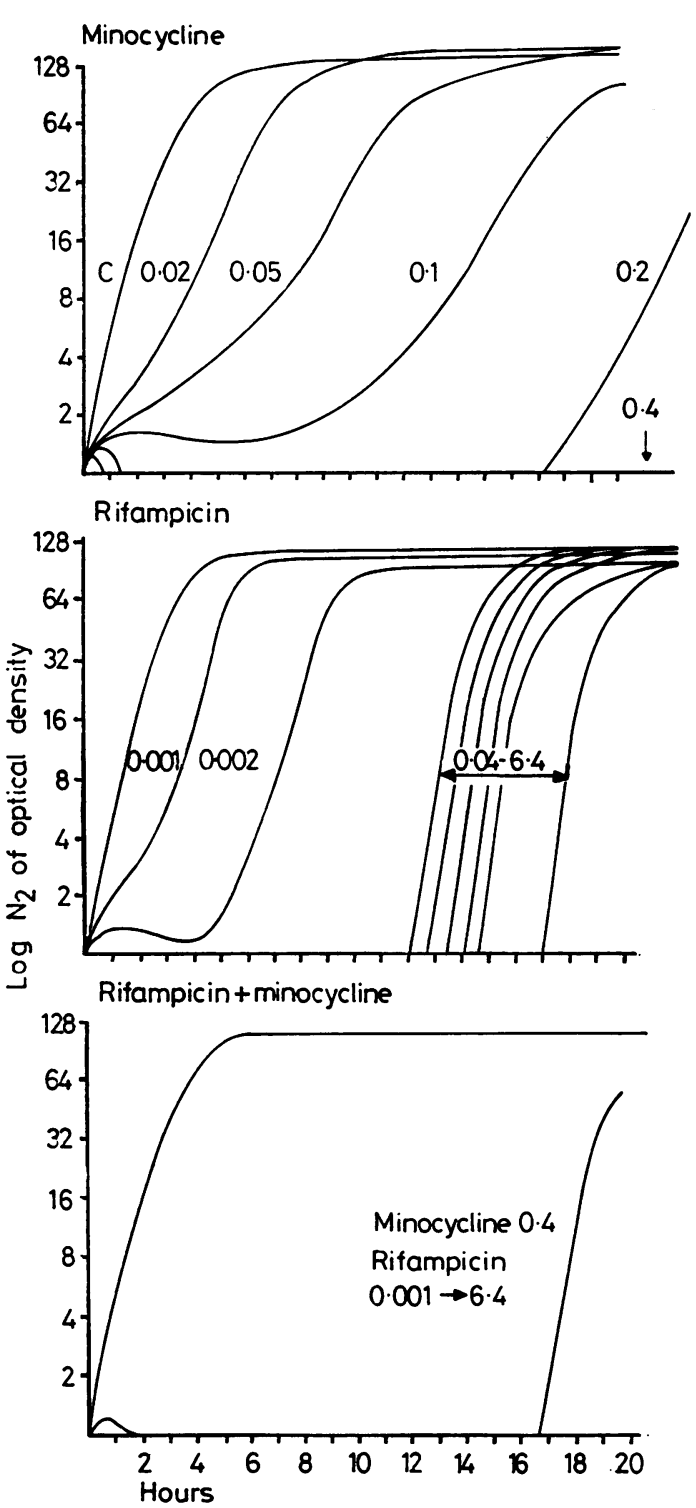

Growth curve of Staphylococcus aureus in the presence of different concentrations of minocycline, rifampicin, and a combination of the two antibiotics (shown as figures lying on the curves). The antibiotics were introduced at time zero (abscess indicated with an arrow). $A$ transitory increase in the optical density may occur at concentrations of minocycline above the MIC.

multiplication was comparable to the controt culture. No bacterial regrowth was seen in the्ष presence of both antibiotics, at concentrations above the MIC of minocycline $(0 \cdot 4 \mu \mathrm{g} / \mathrm{ml})$. Strains resistan to rifampicin appeared at concentrations below this 8 
When the two drugs were used at concentrations below their respective MICs, regrowth occurred. So we cannot speak of synergism because there is no inhibitory activity of minocycline at concentrations below the MIC even in the presence of rifampicin, also added at concentrations below the MIC. The presence of rifampicin did not reduce the sensitivity of the strains to minocycline.

\section{BACTERIAL VIABILITY AND ONE STEP}

RESISTANCE TO RIFAMPICIN

The table shows the results obtained by subculturing the different chambers of the multichambered cartridges on Petri dishes containing blood agar. When the control culture was subcultured at time zero on blood agar plate, we obtained $>1000$ colonies (heavy growth +++ ) and these strains were always susceptible to rifampicin. Any decrease in the number of colonies was described with reference to that initial point (initial inoculum).

When the concentration of minocycline was below its $\operatorname{MIC}(<0.4 \mu \mathrm{g} / \mathrm{ml})$, we observed:

(a) a possible regrowth (not always) even when the concentration of rifampicin was above its MIC (absence of synergism) and it was impossible to predict the regrowth ("skip phenomenon"); in every case of regrowth, the strain was resistant to rifampi$\operatorname{cin}(+++R)$

(b) a constant growth at concentration of rifampicin below its MIC; in these cases, however, all the strains were susceptible to rifampicin $(++\mathbf{S})$.

When the concentration of minocycline was higher than the MIC ( $>0.4 \mu \mathrm{g} / \mathrm{ml})$ we observed:

(a) at concentrations of rifampicin higher than its MIC, the number of colonies were smaller than the initial inoculum; the decrease may be important $( \pm)$ when the two antibiotics are present at high concentrations-for example, minocycline $\geqslant 1.6 \mu \mathrm{g} / \mathrm{ml}$ and rifampicin $\geqslant 0.4 \mu \mathrm{g} / \mathrm{ml}$-and all the strains isolated by subculture were susceptible to rifampicin.

(b) at concentration of rifampicin below its MIC, the density of colonies was smaller $(++)$ than the control $(+++)$ and the decrease in the number of micro-organisms seemed to be due to minocycline alone because any subculture realised from chambers without rifampicin gave the same results $(++)$; all the strains isolated by subculture from chambers containing minocycline at concentrations above the MIC $(0.4 \mu \mathrm{g} / \mathrm{ml})$ remained susceptible to rifampicin.

When the concentrations of both antibiotics were below their MICs $(0.4 \mu \mathrm{g} / \mathrm{ml}$ for minocycline and $0.01 \mu \mathrm{g} / \mathrm{ml}$ for rifampicin all the subcultures were confluent and the bacteria remained susceptible to both antibiotics $(+++\mathbf{S})$.

\section{Discussion}

This study is of limited value since it was carried out using stains isolated at the same hospital which, although of different lysotypes, showed the same profile of sensitivity to the antibiotics, and which probably had the same resistance plasmid. Nevertheless the antimicrobial activity of minocycline on multiresistant strains of Staph aureus (particularly resistance to methicillin) has been shown in other countries. Resistance to minocycline (MIC $\geqslant 3 \mu \mathrm{g} / \mathrm{ml}$ ) associated with certain lysotypes has, however, been described. ${ }^{17} 20-22$ We have shown by the study of growth curves that only minocycline at MIC prevented the regrow th of bacteria resistant to rifampicin. The fall in the number of viable units after 20 hours' contact with a combination of the two antibiotics

Viability and rifampicin sensitivity of Staphylococcus aureus

\begin{tabular}{|c|c|c|c|c|c|c|c|c|c|c|}
\hline \multirow{2}{*}{$\begin{array}{l}\text { Rifampicin } \\
(\mu g / m l)\end{array}$} & \multicolumn{10}{|c|}{ Minocycline $(\mu \mathrm{g} / \mathrm{ml})$} \\
\hline & $0 \cdot 0$ & 0.02 & 0.05 & $0 \cdot 1$ & $0 \cdot 2$ & $0 \cdot 4^{*}$ & $0 \cdot 8$ & $1 \cdot 6$ & $3 \cdot 2$ & $6 \cdot 4$ \\
\hline $6 \cdot 4$ & $(+++\mathbf{R})$ & $(+++\mathbf{R})$ & $(+++\mathbf{R})$ & $(+++\mathbf{R})$ & $(++\mathbf{R})$ & $+\mathbf{S}$ & $+\mathbf{S}$ & $+\mathbf{S}$ & $\pm \mathbf{S}$ & $\pm \mathbf{S}$ \\
\hline $3 \cdot 2$ & $(+++\mathbf{R})$ & $(+++\mathbf{R})$ & $(+++\mathbf{R})$ & $(+++\mathbf{R})$ & $(++\mathbf{R})$ & $+\mathbf{S}$ & $+\mathbf{S}$ & $+\mathbf{S}$ & $\pm S$ & $\pm \mathbf{S}$ \\
\hline $1 \cdot 6$ & $(+++\mathbf{R})$ & $(+++\mathbf{R})$ & $(+++\mathbf{R})$ & $(+++\mathbf{R})$ & $(++\mathbf{R})$ & $+\mathbf{S}$ & $+\mathbf{S}$ & $\pm \mathbf{S}$ & \pm & $\pm S$ \\
\hline $0 \cdot 8$ & $(+++\mathbf{R})$ & $(+++\mathbf{R})$ & $(+++\mathbf{R})$ & $(+++\mathbf{R})$ & $(+++\mathbf{R})$ & $+\bar{S}$ & $+\mathbf{S}$ & $\pm S$ & $\pm S$ & $\pm S$ \\
\hline 0.4 & $(+++\mathbf{R})$ & $(+++\mathbf{R})$ & $(+++\mathbf{R})$ & $(+++\mathbf{R})$ & $(+t+\mathbf{R})$ & $+\mathbf{S}$ & $+\mathbf{S}$ & $\pm \mathbf{S}$ & $\pm \mathbf{S}$ & $\pm S$ \\
\hline $0 \cdot 2$ & $(+++\mathbf{R})$ & $(+++\mathbf{R})$ & $(+++\mathbf{R})$ & $(+++\mathbf{R})$ & $(+++\mathbf{R})$ & $+\mathbf{S}$ & $+\mathbf{S}$ & $+\mathbf{S}$ & $+\mathbf{S}$ & $+\mathbf{S}$ \\
\hline $0 \cdot 1$ & $(+++\mathbf{R})$ & $(+++\mathbf{R})$ & $(+++\mathbf{R})$ & $(+++\mathbf{R})$ & $(+++\mathbf{R})$ & $+\mathbf{S}$ & $+\mathbf{S}$ & $+\mathbf{S}$ & $+\mathbf{S}$ & $+\mathbf{S}$ \\
\hline 0.05 & $(+++\mathbf{R})$ & $(+++\mathbf{R})$ & $(+++\mathbf{R})$ & $(+++\mathbf{R})$ & $(+++\mathbf{R})$ & $+\mathbf{S}$ & $+\mathbf{S}$ & $+\mathbf{S}$ & $+\mathbf{S}$ & $+\mathbf{S}$ \\
\hline 0.02 & $(+++\mathbf{R})$ & $(+++\mathbf{R})$ & $(+++\mathbf{R})$ & $(+++\mathbf{R})$ & $(+++\mathbf{R})$ & $+S$ & $+\mathbf{S}$ & $+\mathbf{S}$ & $+\mathbf{S}$ & $+\mathbf{S}$ \\
\hline $0.01 *$ & $(+++\mathbf{R})$ & $(+++\mathbf{R})$ & $(+++\mathbf{R})$ & $(+++\mathbf{R})$ & $(+t+\mathbf{R})$ & $+\mathbf{S}$ & $+\mathbf{S}$ & $+\mathbf{S}$ & $+\mathrm{S}$ & $+\mathbf{S}$ \\
\hline 0.005 & $+++\mathbf{S}$ & $+++\mathbf{S}$ & $+++\mathbf{S}$ & $+++\mathbf{S}$ & $+++\mathbf{S}$ & $++\mathbf{S}$ & $++\mathbf{S}$ & $++\mathbf{S}$ & $++\mathbf{S}$ & $++\mathbf{S}$ \\
\hline 0.002 & $++\mathbf{S}$ & $+++\mathbf{S}$ & $+++\mathbf{S}$ & $+++\mathbf{S}$ & $+++\mathbf{S}$ & $++\mathbf{S}$ & $-+\mathbf{S}$ & $++\mathbf{S}$ & $++\mathbf{S}$ & $++\mathbf{S}$ \\
\hline $0 \cdot 0$ & $+++\mathbf{S}$ & $+++\mathbf{S}$ & $+++\mathbf{S}$ & $+t+\mathbf{S}$ & $+++\mathbf{S}$ & $++\mathbf{S}$ & $-\perp+\mathbf{S}$ & $++\mathbf{S}$ & $++\mathbf{S}$ & $++\mathbf{S}$ \\
\hline
\end{tabular}

*Minimum inhibitory concentrations (MICs).

In parentheses: non-reproducible data ("skip phenomenon").

Colony count: $t=0-10 ; t=10-100 ;++=100-1000 ;+++=>1000$ or confluent growth.

$\mathbf{R}=$ rifampicin resistance

$\mathbf{S}=$ rifampicin sensitivity. 
was greater than that seen with minocycline alone. The bactericidal activity of rifampicin alone against the strains used in this study was uncertain after 20 hours' incubation, because of the frequent emergence of "one step" resistant bacteria. This in vitro study has shown that a combination of minocycline and rifampicin is of potential value in cases of Staph aureus infection. Further studies will be necessary to define the true therapeutic effect of the combination and the risk of the emergence of resistance in vivo to one or both antibiotics. In animals infected by Staph aureus the development of resistant strains to rifampicin is not so high as predicted in other studies realised in vitro. ${ }^{23}$ This anomaly may be due to the inoculum of the stage in the growth cycle - that is, the exponential phase or not. ${ }^{24}$

Bacterial density in infected subjects is a determining factor (the usual incidence of resistant mutants is $10^{-8}$ organisms $/ \mathrm{ml}$ ). Failures have been described in experimental endocarditis in dogs. ${ }^{25}$ The combination of rifampicin with other antibacterial agents has been studied against a number of bacterial species, ${ }^{26}$ particularly with tetracycline, ${ }^{27}$ nafcillin, ${ }^{28}$ vancomycin, ${ }^{28}$ oleandomycin, ${ }^{29}$ erythromycin, ${ }^{30}$ trimethoprim, ${ }^{31-35}$ nalidixic acid, ${ }^{36}$ and polymixin $B .{ }^{37}$ Rifampicin is of special interest in staphylococcal infection because the good intracellular penetration of the compound results in the death of phagocytosed bacteria. ${ }^{1011}$ The high degree of lipophilicity of rifampicin and of minocycline ${ }^{3738}$ is important in obtaining active concentrations of both compounds at the same site.

\section{References}

1 Bint AJ, George RH, Healing DE, Wise R, Davies M. An outbreak of infection caused by a gentamicin-resistant Staphylococcus aureus. J Clin Pathol 1977;30:165-7.

${ }^{2}$ Kensit JG, Shanson DC. Gentamicin resistance in methicillin sensitive and resistant Staphylococcus aureus. $J$ Antimicrob Chemother 1976;2:311-2.

${ }^{3}$ Porthouse A, Brown DFJ, Smith RG, Rogers T. Gentamicin resistance in Staphylococcus aureus. Lancet 1976; i:20-1.

${ }^{4}$ Shanson DC, Kensit JG, Duke R. Outbreak of hospital infection with a strain of Staphylococcus aureus resistant to gentamicin and methicillin. Lancet 1976;ii:1347-8.

${ }^{5}$ Shannon KP, Phillips I. Gentamicin-resistant Staphylococcus aureus. Lancet $1976 ; . \mathrm{i}: 580-1$.

${ }^{6}$ Speller DCE, Raghunath D, Stephens M, et al. Epidemic infection by a gentamicin resistant Staphylococcus aureus in three hospitals. Lancet 1976; : $: 464-6$.

7 Vogel L, Nathan C, Sweeney HM, Kabins SA, Cohen S. Infections due to gentamicin-resistant Staphylococcus aureus strain in a nursery for neonatal infants. Antimicrob Agents Chemother 1978;13:466-72.

8 Atlas E, Turck M. Laboratory and clinical evaluation of rifampicin. Am J Med Sci 1968;256:247-54.

9 Kunin CM, Brandt D, Wood H. Bacteriologic studies in rifampicin, a new semi-synthetic antibiotic. J Infect Dis
1969;119:132-7.

${ }^{10}$ Mandell GL, Vest TK. Killing of intraleucocytic Staphy오․ lococcus aureus by rifampicin: in vitro and in vive studies. J Infect Dis 1972;125:486-90.

1 Mandell GL. Interaction of intraleukocytic bacteria and antibiotics. $J$ Clin Invest 1973;52:1673-9.

${ }^{12}$ Allen JC. Minocycline. Ann Intern Med 1976;85:482-7.

${ }^{13}$ Brogden RM, Speight TM, Avery GS. Minocycline: G review of its antibacterial and pharmacokinetic proper $\Phi$ ties and therapeutic use. Drugs 1975;9:251-91.

$"$ Phair JP, Hartman RE, Carleton J. Evaluation of the efficacy of minocycline therapy for staphylococcal sofy tissue infection. Antimicrob Agents Chemother 1974;6? $551-3$

1.5 Cappel R, Klastersky J. Bacteriologic and clinical evaly ation of minocycline. A new tetracycline. Current Thert peutic Research Clinical Medicine 1971;13:227-33.

${ }^{16}$ Klastersky J, Danneau D. Bacteriologic evaluation oj minocycline. Chemotherapv 1972;17:51-8.

17 Minuth JN, Holmes TM, Musher DM. Activity of tetracycline, doxycycline and minocycline againer methicillin-susceptible and -resistant staphylococci. Ant microb Agents Chemother 1974;6:411-4.

is Bauer AW, Kirby WM, Sherries JC, Turck M. Antibiotic susceptibility testing by a standardized single dis method. Am J Clin Pathol 1966;45:493-6.

1. Spencer HJ, Stockert J. Weca P, Wilburn R, Price B. Automated antibiotic susceptibility testing with the MS system. In: Jonston HH, Newsom SW, eds. Rap? methods and automation in microbiology. Oxford and New York: Learned information (Europe), 1976;272-50

${ }^{20}$ Phair JP, Carleton J. Susceptibility of staphylococci minocycline in vitro: identification of group III bacteri phage types by characteristic inhibition of growt Infect Immun 1970;2:669-71.

${ }^{21}$ Robertson JM, Reeve ECR. Analysis of resistan mediated by several factors to tetracycline and mine cycline. Genet Res 1972;20:239-52.

${ }^{22}$ Schaefler S, Francois W, Ruby CL. Minocycline resistane्e in Staphylococcus aureus: Effect on phage susceptibilit Antimicrob Agents Chemother 1976;9:600-13.

${ }^{2: 3}$ Lobo MC, Mandell GL. Treatment of experiment staphylococcal infection with rifampicin. Antimicr 8 Agents Chemother 1972;2:195-200.

2 Koch AL, Gross GH. Growth conditions and rifampic susceptibility. Antimicrob Agents Chemother 1979;15 220-8.

${ }^{25}$ Sande MA, Johnson ML. Antimicrobial therapy experimental endocarditis caused by Staphylococes. aureus. J Infect Dis 1975;131:367-75.

${ }^{26}$ Perez Urena MT, Barasoain I, Espinosa M, Garcia $\frac{Z}{E}$ Portoles A. Evaluation of different antibiotic actio combined with rifampicin. Chemotherapy 1975;21:82-10

27 Ariolo V, Pallanza R, Nicholis FB, Furesz S. Experimenta1 data on the interaction between rifampicin and tetray cyclin. Proceedings of the 6th International Congress Chemotherapy (Tokyo) 1969;339-45.

28 Tuazon CU, Lin MYC, Sheagren JN. In vitro activity $\mathbb{9 1}$ rifampin alone and in combination with mafcillin apd vancomycin against pathogenic strains of StaphylococcEs aureus. Antimicrob Agents Chemother 1978;13:759-61

${ }^{29}$ Banic S, Stropnik Z. Synergistic effects of oleandomycin and rifampicin SV in experimental staphylococcs. septicemia in rabbits. Infect Immun 1974;2:160-1.

${ }^{30}$ Peard MC, Fleck DG, Garrod LP, Waterworth P Combined rifampicin and erythromycin for bacterg endocarditis. Br Med J 1970;iv:410-1.

${ }^{31}$ Ariolo V, Berti M, Carniti G, Rossi E, Silvestri LG. Int action between rifampicin and trimethoprim in vitho 
and in experimental infections. $J$ Antimicrob Chemother 1977;3:87-94.

${ }^{32}$ Arioli V, Berti M. Interaction between rifampicin and trimethoprim. J Antimicrob Chemother 1979;5:113-4.

${ }^{33}$ Farrell W, Wils M, Drassar FA. The detection of trimethoprim and rifampicin in combination against Gram-negative rods resistant to gentamicin. J Antimicrob Chemother 1977;3:459-62.

${ }^{34}$ Harvey RJ. Antagonistic interaction of rifampicin and trimethoprim. J Antimicrob Chemother 1978;4:315-27.

${ }^{35}$ Kerry DW, Hamilton-Miller JMT, Brumfitt W. Trimethoprim and rifampicin: in vitro activities separately and in combination. J Antimicrob Chemother 1975;1:417-27.

${ }^{36}$ Greenwood D, Andrew J. Rifampicin plus nalidixic acid: a rational combination for the treatment of urinary infection. J Antimicrob Chemother 1978;4:533-8.

${ }^{37}$ Traub WH, Kleber I. In vitro additive aspect of polymyxin B and rifampicin against Serratia marcescens. Antimicrob Agents Chemother 1975;7:874-6.

${ }^{38}$ Barza M, Brown RB, Shanks C, Gamble C, Weinstein L. Relation between lipophilicity and pharmacological behavior of minocycline, doxycycline, tetracycline and oxytetracycline in dogs. Antimicrob Agents Chemother $1975 ; 8: 713-20$.

Requests for reprints to: Professor E Yourassowsky, Hôpital Universitaire Brugmann, Service de Biologie Clinique, Avenue JJ Crocq 1, 1020 Bruxelles, Belgique.

\section{Reports and Bulletins prepared by the Association of Clinical Biochemists}

The following reports and bulletins are published by the Association of Clinical Biochemists. They may be obtained from The Publishing Department, British Medical Journal (ACB Technical Bulletins), BMA House, Tavistock Square, London WC1H 9JR. Overseas readers should remit by British Postal or Money Order.

SCIENTIFIC REVIEWS (price $£ 1 \cdot 00 / \$ 2.00$ each)

1 The assessment of thyroid function March 1971 FV FLYNN and JR HOBBS

2 Renal function tests suitable for clinical practice January 1972 FL MITCHELL, N VEALL, and RWE WATTS

3 Biochemical tests for the assessment of fetoplacental function May 1975 CE WILDE and RE OAKEY

4 Test of exocrine pancreatic function March 1977 AH GOWENLOCK

5 Assay of cholinesterase in clinical chemistry March 1979 ELSIE SILK, J KING, and MARY WHITTAKER

TECHNICAL BULLETINS (price $£ 1 \cdot 00 / \$ 2.00$ each)

22 Bilirubin standards and the determination of bilirubin by manual and technicon AutoAnalyzer methods January 1971 BARBARA BILLING, RUTH HASLAM, and N WALD

23 Interchangeable cells for spectrophotometers and fluorimeters September 1971 ss BROWN and AH GOWENLOCK

24 Simple tests to detect poisons March 1972 BW MEADE $e t$ al.

25 Blood gas analysers May 1972 K DIxON

26 Kits for enzyme activity determination September 1972 SB ROSALKI and D TARLOW

27 Assessment of pumps suitable for incorporation into existing continuous flow analytical systems November 1972 A FLECK et al.

28 Routine clinical measurements of transferrin in human serum September 1973 K DIXON
29 Control materials for clinical biochemistry (5th edition) September 1973 JF STEVENS

30 Notes on the quality of performance of serum cholesterol assays September 1973 ss BROWN

31 Determination of uric acid in blood and in urine July 1974 RWE WATTS

32 A survey of amino acid analysers readily available in the United Kingdom September 1974 JE CARLYLE and $P$ PURKISS

33 Definitions of some words and terms used in automated analysis November 1974 A FLECK, R ROBINSON, SS BROWN, and JR HOBBS

34 Measurement of albumin in the sera of patients January 1975 LINDA SLATER, PM CARTER, and JR HOBBS

35 Investigation of the validity of temperature correction factors for serum aspartate and alanine transaminases March 1975 SB ROSALK1 et al.

36 Factors influencing the assay of creatinine November 1975 JGH COOK

37 A survey of enzyme reaction rate analysers readily available in the United Kingdom July 1977 RA SAUNDERS and RF BURNS

38 Transport of specimens for clinical chemistry analysis November 1977 P WILDING, JF ZILVA, and CE WILDE

39 A scheme for the evaluation of diagnostic kits May 1978 PH LLOYD

40 A practical guide to gamma-counting in radioimmunoassay January 1980 CE WILDE and D OTTEWELL

41 The use of biochemical tests in the diagnosis of disorders of calcium metabolism July 1980 ANGELA FAIRNEY 